\title{
Evaluating the in vitro efficacy of bovine lactoferrin products against SARS-CoV-2 variants of concern
}

\author{
Jesse W. Wotring, ${ }^{1 *}$ Reid Fursmidt, ${ }^{2 *}$ Loren Ward, ${ }^{3}$ and Jonathan Z. Sexton ${ }^{1,2,4,5} \dagger$ \\ ${ }^{1}$ Department of Medicinal Chemistry, College of Pharmacy, University of Michigan, Ann Arbor 48109 \\ ${ }^{2}$ Department of Internal Medicine, Gastroenterology, Michigan Medicine at the University of Michigan, Ann Arbor 48109 \\ ${ }^{3}$ Glanbia Nutritionals, Twin Falls, ID 83301 \\ ${ }^{4}$ UM Center for Drug Repurposing, University of Michigan, Ann Arbor 48109 \\ ${ }^{5}$ Michigan Institute for Clinical and Health Research (MICHR), University of Michigan, Ann Arbor 48109
}

\begin{abstract}
Bovine lactoferrin (bLF), a naturally occurring glycoprotein found in milk, has bioactive characteristics against many microbes, viruses, and other pathogens. Bovine lactoferrin strongly inhibits SARS-CoV-2 infection in vitro through direct entry inhibition and immunomodulatory mechanisms. This study reports on the anti-SARS-CoV-2 efficacy of commercially available bLF and common dairy ingredients in the human lung cell line H1437 using a custom high-content imaging and analysis pipeline. We also show for the first time that bLF has potent efficacy across different viral strains including the South African B.1.351, UK B.1.1.7, Brazilian P.1, and Indian Delta variants. Interestingly, we show that bLF is most potent against the B.1.1.7 variant [half-maximal inhibitory concentration $\left(\mathrm{IC}_{50}\right)=3.7 \mu \mathrm{g} / \mathrm{mL}$ ], suggesting that this strain relies on entry mechanisms that are strongly inhibited by bLF. We also show that one of the major proteolysis products of bLF, lactoferricin B 17-41, has a modest anti-SARS-CoV-2 activity that could add to the clinical significance of this protein for SARS-CoV-2 treatment as lactoferricin is released by pepsin during digestion. Finally, we show that custom chewable lactoferrin tablets formulated in dextrose or sorbitol have equivalent potency to unformulated samples and provide an option for future human clinical trials. Lactoferrin's broad inhibition of SARS-CoV-2 variants in conjunction with the low cost and ease of production make this an exciting clinical candidate for treatment or prevention of SARS-CoV-2 in the future.
\end{abstract}

Key words: lactoferrin, SARS-CoV-2, variants of concern

Received September 4, 2021.

Accepted December 7, 2021.

*These authors contributed equally to this work.

†Corresponding author: jzsexton@med.umich.edu

\section{INTRODUCTION}

Lactoferrin ( $\mathbf{L F})$ is a naturally occurring cationic glycoprotein. It is found in the milk of most mammals and is part of the innate immune system. Lactoferrin displays a wide variety of bioactive characteristics endogenously as part of the innate immune system (Legrand and Mazurier, 2010) or as a dietary supplement (Moreno-Expósito et al., 2018). The established bioactivities of exogenous LF are its ability to inhibit microbial growth, adhesion, and aggregation via iron sequestration (Parrow et al., 2013). Lactoferrin also works through iron-independent mechanisms (Rosa et al., 2017), offering protection against both enveloped and nonenveloped viruses via direct binding to host cells or viral particles (Valenti and Antonini, 2005). Lactoferrin also acts through other immunomodulatory mechanisms to support cellular defense mechanisms (Siqueiros-Cendón et al., 2014).

Bovine lactoferrin (bLF) displays broad-spectrum antiviral activity both in vitro and in vivo (van der Strate et al., 2001; Jenssen and Hancock, 2009; Wakabayashi et al., 2014). In vitro results show that bLF inhibits respiratory syncytial virus (RSV), influenza A virus (H3N2, H1N1, H3N2), as well as avian influenza A virus (H5N1), rotavirus, adenovirus, poliovirus, echovirus, herpes simplex virus (HSV-1, HSV-2), and other viruses (Wakabayashi et al., 2014). Bovine lactoferrin has also shown antiviral activity in human clinical trials. For example, orally administered bLF has been shown to improve the severity of viral infections including rotavirus (Egashira et al., 2007) and norovirus (Wakabayashi et al., 2014). However, additional studies are needed to understand the potential of bLF as a broad-spectrum antiviral.

A key benefit to the broad antiviral efficacy of LF is its potential for the prevention or treatment of emerging diseases. This is especially important when there are limited treatment options, or when the treatment options are too costly for widespread use. A highly rel- 
evant example of a recently emergent disease is SARSCoV-2, which causes COVID-19 and has resulted in a global pandemic (Spinelli and Pellino, 2020). In December 2019, SARS-CoV-2 emerged as a novel betacoronavirus and has since caused more than 600,000 deaths in the United States and over 4 million deaths worldwide as of July 2021 (Dong et al., 2020).

Given the broad-spectrum antiviral efficacy and safety (Nappi et al., 2009; Cutone et al., 2020), minimal side effects (Nappi et al., 2009), and commercial availability of bLF, several review papers have suggested using bLF as a prophylactic or postexposure treatment for SARS-CoV-2 infection (Chang et al., 2020; Wang et al., 2020).

The potential for oral bLF as an antiviral agent for SARS-CoV-2 infection is supported by several previous research observations including in vitro work on the related betacoronavirus SARS-CoV. When SARS-CoV emerged in 2002, researchers studied the ability of bLF to inhibit SARS-CoV in vitro (Lang et al., 2011). Entry of SARS-CoV into cells is dependent on viral association with the anionic heparan sulfate proteoglycan (HSPG) on cell surfaces that act as a prerequisite cofactor for subsequent binding of spike protein to angiotensin-converting enzyme 2 (ACE2) receptor and cell infection (Lang et al., 2011). Using HEK293E/ACE2-Myc cells, researchers were able to show that LF inhibited SARS$\mathrm{CoV}$ in vitro in a dose-dependent manner (Lang et al., 2011). Other research has confirmed that bLF association with cell surface HSPG inhibits several additional strains of $\mathrm{CoV}$ such as $\mathrm{HCoV}-\mathrm{OC} 43$, HCoV-NL63, and $\mathrm{HCoV}-229 \mathrm{E}$ (Hu et al., 2021) from HSPG association and subsequent binding of spike protein with ACE2.

Recently, we have shown that bLF also has strong in vitro efficacy against SARS-CoV-2, which employs many of the same mechanisms for entry and replication as SARS-CoV. Our image-based high-throughput screen of 1,425 compounds identified bLF as a top hit with a half-maximal inhibitory concentration $\left(\mathbf{I C}_{50}\right)$ of $308 \mathrm{n} M(26.8 \mu \mathrm{g} / \mathrm{mL})$ in the Huh7 human liver cell (Mirabelli et al., 2021). This antiviral efficacy was observed in several other human cell lines, including LNCaP (prostate), Caco2 (colorectal), and iAEC2 (alveolar). Bovine lactoferrin's efficacy appears to be independent of cell lineage, which is noteworthy, as many other antiviral hits have proven to be dependent on cell lineage and less relevant for clinical study (Tzou et al., 2020; Tworowski et al., 2021). The efficacy of bLF was shown to be multimodal, as there were both direct binding inhibition and host cell immunomodulation, which limited infection. Viral inhibition was not observed upon treatment with transferrin, a related iron-binding protein, which confirmed an iron-independent mechanism of action (Mirabelli et al., 2021).
Despite a widespread vaccine rollout in the United States, there is still an urgent need for alternative therapies for the treatment or prevention of SARS-CoV-2 worldwide. Currently, the only Food and Drug Administration-approved drug for the treatment of SARSCoV-2 infection is remdesivir, which must be administered intravenously and has not shown high clinical efficacy (Spinner et al., 2020). Unfortunately, according to the Organization for Economic Co-operation and Development (OECD), much of the developing world will not reach mass immunization until 2024 (OECD, 2021), leaving a large population of people vulnerable to the disease. Additionally, the emergence of SARSCoV-2 variants with increased virulence has been a cause for concern, as they may be less susceptible to the vaccine. In particular, the South African B.1.351, UK B.1.1.7, Brazilian P.1, and Delta variants have shown to be more virulent and potentially more deadly than previous viral strains (Challen et al., 2021; Davies et al., 2021). An orally available therapeutic that covers emerging strains, such as bLF, would be ideal for treating SARS-CoV-2 in areas without widespread vaccination or if new strains escape the vaccine.

The goal of this study was to expand upon the observation of bLF's potent anti-SARS-CoV-2 efficacy in vitro with a more thorough examination of bLF as well as screen commercially available milk products for antiviral activities. Given the efficacy of bLF in previous experiments, we hypothesized that other purified bioactive milk protein products may also have antiviral activity against SARS-CoV-2. Moreover, we aimed to evaluate the efficacy of bLF and its proteolytic product lactoferricin B against several of the new SARS-CoV-2 variants of concern including B.1.1.7, B.1.351, and P.1. Finally, we sought to investigate formulation strategies for a chewable bLF tablet-placebo pair that retain efficacy in vitro and could be used for a SARS-CoV-2 human clinical trial in the future.

\section{MATERIALS AND METHODS}

\section{Dairy Products}

Bovine lactoferrin and other dairy products were obtained from Glanbia Nutritionals as powders. Iron saturation for LF samples was provided by Glanbia Nutritionals and ranged between 15 and $18 \mathrm{mg}$ of iron/100 g of powder. Fresh stock solutions were made before each experiment to avoid degradation over time. Lactoferricin B 17-41 (lactoferricin B25) was obtained from Bachem (product no. 4087382). All dairy product samples, including lactoferricin B, were solubilized in complete cell culture medium [Dulbecco's modified Eagle medium (DMEM; Thermo Fisher Scientific), 
$10 \%$ fetal bovine serum, $1 \times$ penicillin-streptomycin] at $1 \mathrm{mg} / \mathrm{mL}$, sterilized using $20-\mu \mathrm{m}$ syringe filters, and diluted by hand before adding to cells.

\section{Cells and Virus}

$\mathrm{H} 1437$ and Vero E6 cells were maintained at $37^{\circ} \mathrm{C}$ and $5 \% \mathrm{CO}_{2}$ in DMEM supplemented with $10 \%$ heatinactivated fetal bovine serum (10-437-028, Fisher Scientific) and $1 \times$ penicillin-streptomycin (15140122, Gibco). Cells were tested for mycoplasma contamination before usage and the results were negative. SARSCoV-2 strains (WA1, B.1.1.7, B.1.351, P.1, and Delta) were obtained from BEI Resources and were propagated in Vero E6 cells. Viral titers were determined by median tissue culture infectious dose $\left(\mathrm{TCID}_{50}\right)$ assays in Vero-E6 cells using the Reed and Muench (1938) method by microscopic scoring. Viral titers for stocks ranged between $10^{7}$ to $10^{8} \mathrm{TCID}_{50} / \mathrm{mL}$. All experiments using SARS-CoV-2 were conducted at the University of Michigan under Biosafety Level 3 protocols in compliance with containment procedures in laboratories for use by the University of Michigan Institutional Biosafety Committee and Environment, Health and Safety.

\section{Anti-SARS-CoV-2 Bioassay}

H1437 cells were seeded onto 384-well plates (6057300, Perkin Elmer) at a density of 5,000 cells/well and allowed to attach overnight at $37^{\circ} \mathrm{C}$ and $5 \% \mathrm{CO}_{2}$. The total volume per well of cell culture medium was $50 \mu \mathrm{L}$. The next day, $10 \mu \mathrm{L}$ of medium was removed from each well and replaced with $10 \mu \mathrm{L}$ of medium containing LF and milk products dissolved to an appropriate concentration. Cells were returned to the incubator for $24 \mathrm{~h}$ for milk product pretreatment. Following pretreatment, cells were transferred to a Biosafety Level 3 facility and infected with SARS-CoV-2 at a multiplicity of infection (MOI) of 5. Cells were left at room temperature for $30 \mathrm{~min}$, then transferred to an incubator for $48 \mathrm{~h}$ postinfection. After the infection period, cells were fixed with $4 \%$ paraformaldehyde for $30 \mathrm{~min}$ at room temperature, permeabilized with $0.3 \%$ Triton X-100 for $20 \mathrm{~min}$, washed $2 \times$ with cold PBS, and blocked with antibody buffer (1.5\% BSA, $1 \%$ goat serum, and $0.0025 \%$ Tween 20). The 384-well plates were then sealed, surface decontaminated, and transferred to a BSL2 space for overnight labeling with anti-nucleocapsid SARS-CoV-2 primary antibody at $+4^{\circ} \mathrm{C}$ (catalog number ABIN6952432, Antibodies Online). Following primary antibody staining, cells were washed $2 \times$ with PBS and stained with an optimized fluorescent dye set containing 1:1,000 Hoechst 33342 pentahydrate (bisbenzimide) for nuclear labeling and 1:1,000 secondary antibody Alexa-647 (goat anti-mouse, A21235, Thermo Fisher) for viral labeling for $30 \mathrm{~min}$ at room temperature. Cells were washed $2 \times$ with PBS, then left in a final volume per well of $50 \mu \mathrm{L}$ of PBS in preparation for fluorescent imaging.

\section{Fluorescence Imaging}

Fluorescent stained plates were imaged using both Yokogawa Cell Voyager 8000 (CV8000) and Thermo Fisher CX5 high-content microscopes at $20 \times$ and $10 \times$ magnification, respectively. The Yokogawa CV8000 imaging was performed with 2 excitation laser lines $(405 / 640 \mathrm{~nm})$ with a spinning disk confocal and 100-ms exposure times. Laser power was adjusted to produce the optimal signal-to-noise ratio for both channels. Maximum intensity projection images were generated from 5 confocal planes with a $3-\mu \mathrm{m}$ step size. Laser autofocus was performed on a total of $\mathrm{n}=9$ fields per well, which accounts for roughly $80 \%$ of the total well area. The Thermo Fisher CX5 images were taken with light-emitting diode excitation $(386 / 23 \mathrm{~nm}, 650 / 13$ $\mathrm{nm})$. Exposure times were varied to achieve optimal signal-to-background ratio and images were collected at a single Z-plane as determined by image-based autofocus on the nuclear channel. As with CV8000 images, 9 fields per well were collected.

\section{Image Processing}

Images were processed using the open-source cell segmentation software CellProfiler 4.0 (McQuin et al., 2018). A pipeline was designed to identify both nuclei (Hoechst 33342 channel) and viral objects (Alexa Fluor 647 channel). Infected cells were identified using the relate objects module, where any nucleus contained within a viral object was defined as infected. Cell counts and infected cell counts were exported at the field level and joined with treatment metadata for further analysis.

\section{Dose-Response Analysis}

Field-level image data were grouped at the well level using Excel (Microsoft Corp.). A raw percent infection score was determined by taking a ratio of infected cells to total cell counts per well and multiplying by 100 . Due to the difference in raw infection percentages observed with different viral strains, data were normalized to the virally infected control such that the highest raw percentage of infected cells would be equivalent to $100 \%$ infection. Dose-response curves for this data were fitted in GraphPad Prism 9.0 (GraphPad Software) using a semi-log 4-parameter variable slope model. 


\section{Statistical Analysis and Hypothesis Testing}

All statistical analyses and hypothesis testing was performed using GraphPad Prism 9.0 (GraphPad Software). Specifics, including sample sizes and other important data, are included within the text of the figure legends.

\section{Lactoferrin Chewable Tablets for Human Clinical Studies}

Custom mixed berry LF chewable tablets were provided by Glanbia Nutritionals. These tablets were formulated with either sorbitol or dextrose containing $25 \%$ bLF. Additionally, placebo tablets (not containing LF) were generated using dextrose or sorbitol as excipients.

\section{RESULTS}

\section{Anti-SARS-CoV-2 Efficacy of Bovine Milk Products}

Given the high efficacy of purified bLF in vitro, we were interested in assessing the anti-SARS-CoV-2 efficacy of other commercially available dairy products containing bLF. These products included whey protein isolates, concentrates, Bioferrin 2000, and several other products with higher levels of bLF. We hypothesized that these dairy products might have higher efficacy than bLF alone due to the presence of additional bioactive proteins. To evaluate the efficacy, we designed an image-based SARS-CoV-2 inhibition assay using the human lung adenocarcinoma cell line H1437 (Figure 1).
This human cell line was chosen due to its expression of ACE2 and TMPRSS2, the 2 primary entry factors necessary for SARS-CoV-2 infection (Hoffmann et al., 2020). Briefly, cells were plated onto 384 -well plates before overnight incubation. Then, protein products were added in 10-point, 2-fold dilutions $(\mathrm{n}=3)$ from a top concentration of $400 \mu \mathrm{g} / \mathrm{mL}$ and allowed to incubate for another $24 \mathrm{~h}$. Next, cells were infected with SARSCoV-2 WA1 strain at a MOI of 5 and incubated for 48 h. Cells were then fixed and stained with Hoechst 33342 and anti-nucleocapsid protein (NP) antibody to identify nuclei and viral NP. Plates were imaged using highcontent fluorescence microscopy at $20 \times$ magnification (9 fields per well) and processed using the open-source cell segmentation software CellProfiler 4.0 to identify infected and uninfected cells. Well-level raw percent infection was calculated by taking a ratio of infected to total cell counts per well. Dose-response curves were generated using data normalized to the average of the viral control $(23.5 \%$ raw infection $=100 \%$ normalized infection). A flow diagram for this process is shown in Figure 1A. Representative images for infected and uninfected controls are shown in Figure 1B.

In total, 9 bioactive milk protein samples obtained from Glanbia Nutritionals were evaluated for concentration-responsive anti-SARS-CoV-2 activity in this model. The results for this experiment are shown in Table 1 with $\mathrm{IC}_{50}$ values reported when applicable. Dose-response curves, as well as representative images for efficacious samples, are included in Figure 2A and $2 \mathrm{~B}$, respectively. Five of the samples had efficacy with $\mathrm{IC}_{50}$ values ranging from 21.8 to $156.0 \mu \mathrm{g} / \mathrm{mL}$, and none were acutely cytotoxic up to $400 \mu \mathrm{g} / \mathrm{mL}$. Of
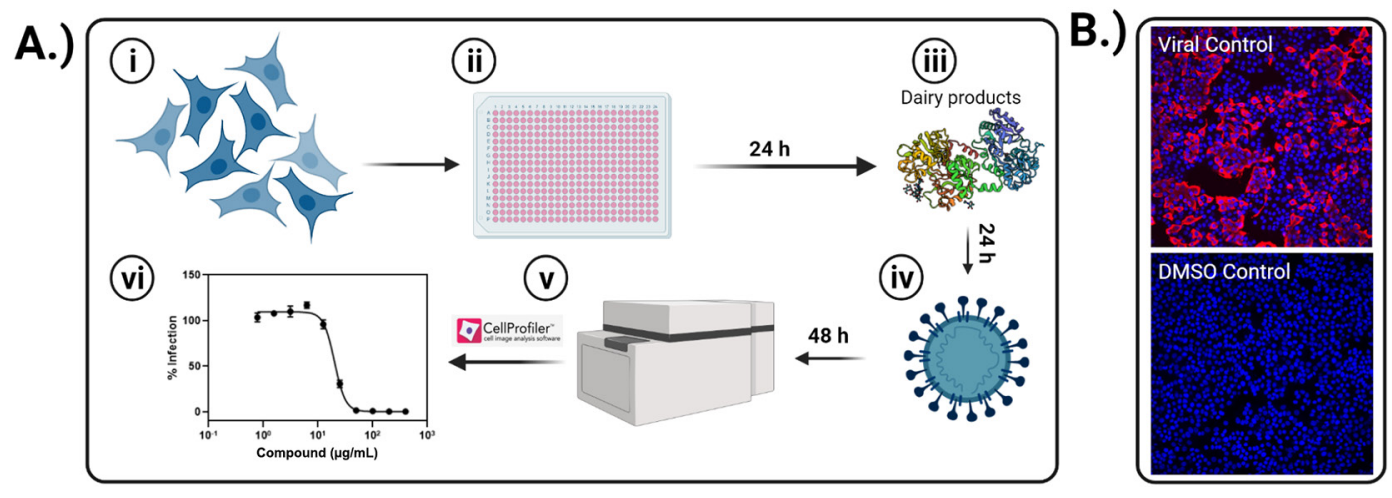

Figure 1. Image-based SARS-CoV-2 inhibition assay. (A) H1437 human lung cells (i) were plated onto 384-well plates and incubated overnight (ii). Then, dairy products were added in a 10-point, 2 -fold dilution series $(\mathrm{n}=3)$ from a top concentration of $400 \mu \mathrm{g} / \mathrm{mL}$ and allowed to preincubate overnight (iii). Next, SARS-CoV-2 WA1 strain was added at a multiplicity of infection of 5 and incubated for $48 \mathrm{~h}$ postinfection (iv) before fixing, staining, and fluorescence imaging to identify infected cells (v). Finally, the image analysis software CellProfiler 4.0 (McQuin et al., 2018) was used to quantify infection and generate dose-response curves for dairy products against SARS-CoV-2 (vi). The figure was generated using BioRender.com. (B) Representative images for viral and uninfected controls (blue = cell nuclei, red = viral nucleocapsid protein). Images were taken using a Yokogawa CV8000 high-content microscope at $20 \times$ magnification. DMSO $=$ dimethyl sulfoxide. Error bars represent SEM. 
Table 1. Efficacy of dairy products against SARS-CoV-2 $2^{1}$

\begin{tabular}{|c|c|c|c|c|c|}
\hline Product name & Product ID & $\% \mathrm{bLF}$ & $\begin{array}{l}\text { Sample } \mathrm{IC}_{50} \\
(\mu \mathrm{g} / \mathrm{mL})\end{array}$ & $\begin{array}{c}\mathrm{CC}_{50} \\
(\mu \mathrm{g} / \mathrm{mL})\end{array}$ & $\begin{array}{c}\text { bLF-only } \mathrm{IC}_{50}{ }^{2} \\
(\mu \mathrm{g} / \mathrm{mL})\end{array}$ \\
\hline Whey protein isolate & $11-20-014-01$ & 0.14 & $>400$ & $>400$ & $\mathrm{NA}$ \\
\hline Whey protein concentrate $\mathrm{A}$ & 11-20-014-02 & 0.48 & $>400$ & $>400$ & NA \\
\hline Bioferrin 2000 & $11-20-014-04$ & 91.56 & $21.8 \pm 1.2$ & $>400$ & $20.0 \pm 1.1$ \\
\hline Bioferrin $2000^{3}$ & $11-20-014-05$ & 93.07 & $22.0 \pm 2.5$ & $>400$ & $20.4 \pm 2.4$ \\
\hline Lactoferrin concentrate & $11-20-014-06$ & 31.50 & $72.5 \pm 13.9$ & $>400$ & $22.9 \pm 4.4$ \\
\hline Lactoferrin enriched whey protein isolate sample B & 11-20-014-09 & 46.61 & $51.1 \pm 2.3$ & $>400$ & $23.8 \pm 1.1$ \\
\hline
\end{tabular}

${ }^{1}$ Results from the anti-SARS-CoV-2 bioassay. The percentage of bovine lactoferrin (bLF) in each sample is included, as well as their $50 \%$ inhibition concentrations $\left(\mathrm{IC}_{50} \pm \mathrm{SEM}\right)$ and $50 \%$ cytotoxic concentrations $\left(\mathrm{CC}_{50}\right)$.

${ }^{2}$ Calculated assuming sample efficacy was from bLF alone by taking the product of the \%bLF and the sample IC 50 . NA $=$ not applicable.

${ }^{3}$ Two different batches of Bioferrin 2000 (Glanbia Nutritionals) were evaluated.

note, each of the efficacious protein products contained a significant percentage of bLF and their $\mathrm{IC}_{50}$ were correlated with this value (Figure $3 \mathrm{~A}, \mathrm{r}=-0.88, P=$ 0.049). Additionally, if the sample $\mathrm{IC}_{50}$ are normalized to their \%bLF (bLF-only $\mathrm{IC}_{50}$, Table 1 and Figure $3 \mathrm{~B}$ ), we observed no significant differences in the resultant values as determined by one-way ANOVA $\left(F_{4,10}=\right.$ $0.68, P=0.62)$. Our data suggest that the other dairy components in these products do not possess any antiSARS-CoV-2 activity up to $400 \mu \mathrm{g} / \mathrm{mL}$ and that the efficacy is entirely dependent on bLF. This provides strong support for the high specificity of bLF antiSARS-CoV-2 activity, which is not observed for other bioactive milk proteins.

\section{bLF Inhibits P.1, B.1.1.7, B.1.351, and Delta Variants}

To improve clinical relevance and translatability, we tested bLF against some of the most common SARSCoV-2 variants of concern. These included the WA1 variant (US 2020 strain), the B.1.1.7 variant (United Kingdom strain), B.1.351 variant (South Africa strain), P.1 variant (Japan/Brazil strain), and Delta variant (Indian strain). Notably, each of these variants includes modifications to the SARS-CoV-2 spike protein which endangers the efficacy of all newly produced vaccines (Aleem et al., 2021). Furthermore, each of these strains shows reduced neutralization by vaccination sera $(\mathrm{Su}-$ pasa et al., 2021; Virtanen et al., 2021).

Using the previously described anti-SARS-CoV-2 bioassay, we evaluated the efficacy of bLF against these common viral strains $(\mathrm{MOI}=5)$ in 10 -point, 2 -fold dilution from a top concentration of $200 \mu \mathrm{g} / \mathrm{mL}$ (n $=4$ ). We found that bLF was efficacious against all variants tested, with $\mathrm{IC}_{50}$ values ranging from 3.7 to $44.4 \mu \mathrm{g} / \mathrm{mL}$ (Figure $4 \mathrm{~A}$ ). We also found that bLF was capable of preventing cell death caused by the virus
(Figure 4B), as a result of the decreased cell infection. Interestingly, infection with the different viral strains at an equivalent MOI resulted in different raw infection percentages for H1437 cells and was particularly high for the B.1.351 variant (Figure 4C). Of note, infection with several of the strains including B.1.1.7, P.1 and Delta did not result in a cytopathic effect, and therefore bLF did not positively influence viability for these strains. The differential infectivity of these strains is also apparent in Figure 4D, which shows representative images for viral controls and infected cells treated with $200 \mu \mathrm{g} / \mathrm{mL}$ bLF. These images also show a significant reduction in the number of viral nucleocapsid proteinpositive cells upon treatment with bLF. The potency of bLF was highest against the B.1.1.7 variant $\left(\mathrm{IC}_{50}=\right.$ $3.7 \mu \mathrm{g} / \mathrm{mL})$ and lowest against the P.1 variant $\left(\mathrm{IC}_{50}=\right.$ $31.9 \mu \mathrm{g} / \mathrm{mL}$ ), indicating that mutations affecting the viral spike protein overlap with the mechanism of bLF inhibition. Although the potency was not the highest against the B.1.351 strain $\left(\mathrm{IC}_{50}=31.0 \mu \mathrm{g} / \mathrm{mL}\right)$, the drastic reduction in infection demonstrates that bLF works against strains with higher infectivity and has broad-spectrum activity against SARS-CoV-2 variants.

\section{Lactoferricin B Has Modest Anti-SARS-CoV-2 Efficacy}

Orally administered bLF has a relatively short halflife in vivo $(\sim 10 \mathrm{~min})$ as a result of rapid peptic digestion by the gastrointestinal tract (Elzoghby et al., 2020). The major fragment of this peptic digestion is a 1.5-kDa peptide called lactoferricin B (lactoferricin B 17-41), which has been shown to have potent antimicrobial activity as a result of its highly cationic nature. With this in mind, we evaluated synthetic lactoferricin $\mathrm{B}$ in the image-based antiviral bioassay to determine if it also had efficacy against SARS-CoV-2. Antiviral ac- 
A.)
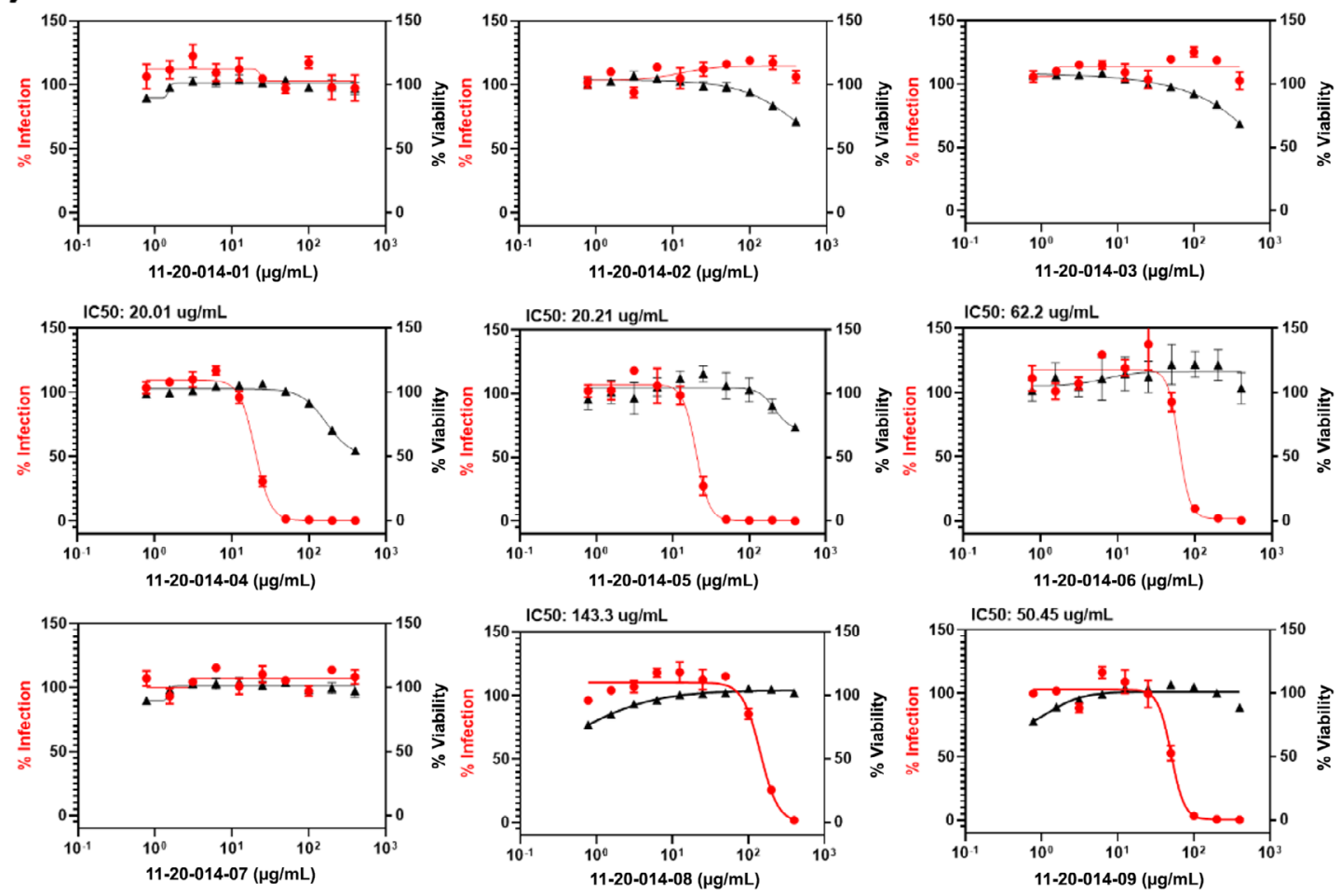

B.)
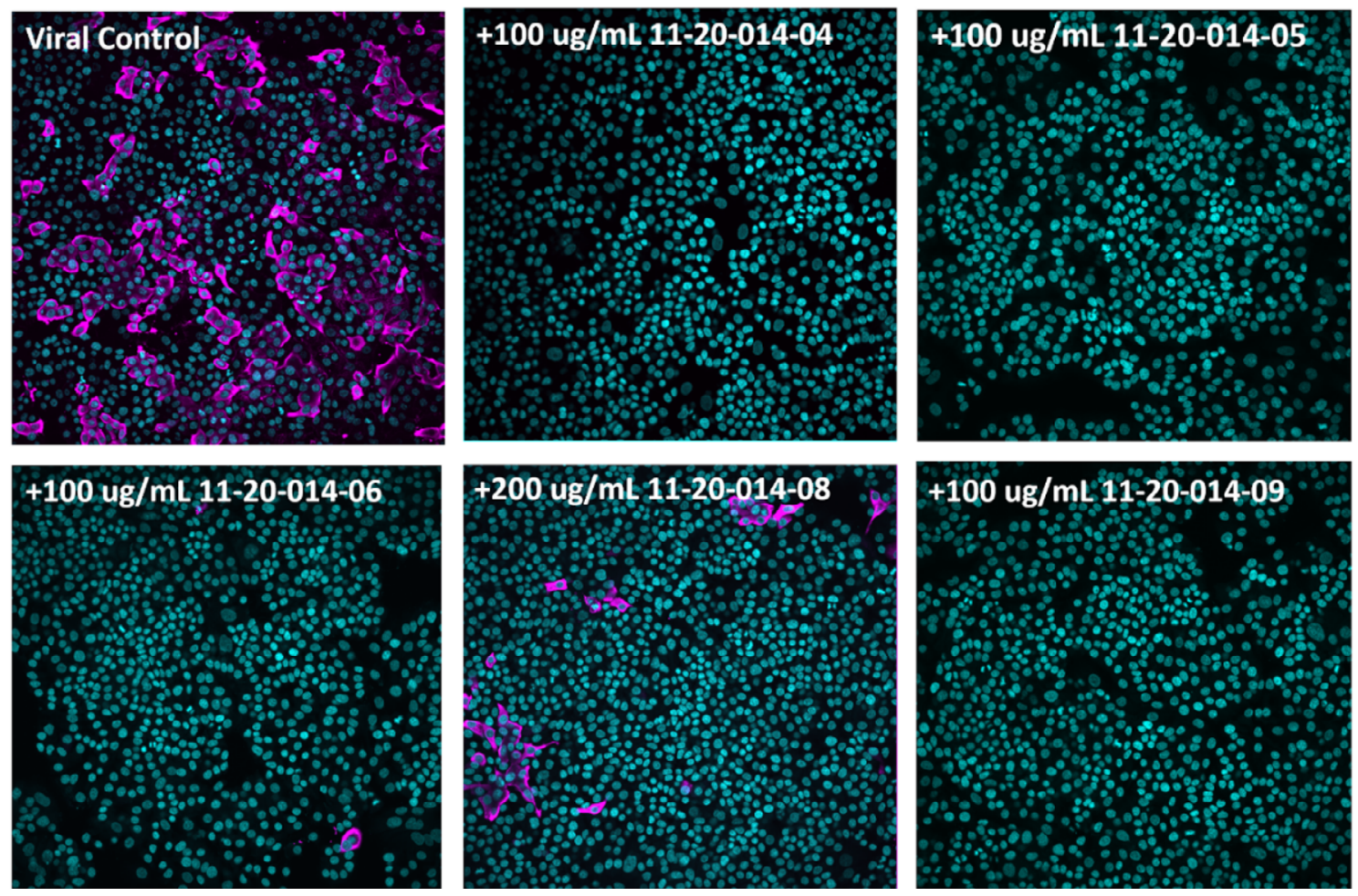

Figure 2. Anti-SARS-CoV-2 activity of dairy products. (A) Dose-response curves for dairy products. Data shown are the mean \pm SEM of 10-point, 2 -fold dilution series $(\mathrm{n}=3$ replicates per condition). Curve fitting was performed using GraphPad Prism 9.0 using a semi-log 4-parameter variable slope model. (B) Representative images for efficacious samples (e.g., 11-20-014-04) and the viral control. Cell nuclei are shown in cyan; viral nucleocapsid protein is shown in magenta. Images shown were taken on a Yokogawa CV8000 high-content microscope at $20 \times$ magnification and colored using ImageJ (National Institutes of Health). 
A.)

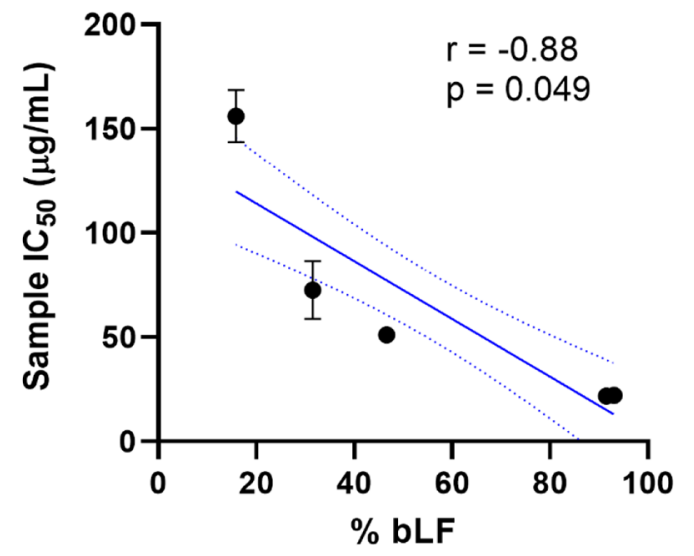

B.)

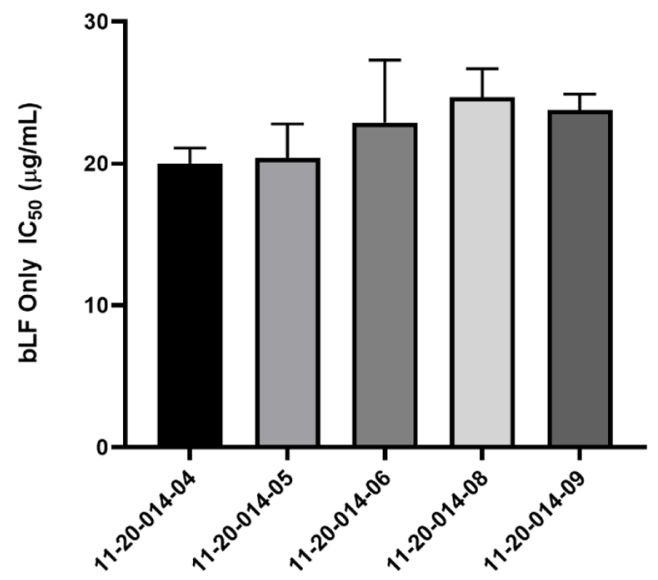

Figure 3. Sample efficacy depends on bovine lactoferrin (bLF). (A) Pearson correlation for sample half-maximal inhibitory concentration $\left(\mathrm{IC}_{50}\right)$ versus percentage $\mathrm{bLF}(\mathrm{r}=-0.88, P=0.049)$. (B) bLF-only $\mathrm{IC}_{50}$ for efficacious samples calculated by taking the product of the fraction bLF and the sample $\mathrm{IC}_{50}$. There were no statistically significant differences between the group means as determined by one-way ANOVA $\left(F_{4,10}\right.$ $=0.68, P=0.62)$. Error bars represent SEM.

tivity was evaluated against the WA1, B.1.1.7, B.1.351, and P. 1 variants at 3 different concentrations $(200,100$, and $50 \mu \mathrm{g} / \mathrm{mL}$ ) with $\mathrm{n}=4$ replicates per condition. We found that lactoferricin has statistically significant antiviral activity against each of the viral strains (Figure 5), with $\mathrm{IC}_{50}$ values near or exceeding the $200 \mu \mathrm{g} /$ $\mathrm{mL}$ top concentration. The potency of lactoferricin $\mathrm{B}$ is much lower than LF; however, the activity is significant and could contribute to the overall efficacy of LF in vivo.

\section{Chewable bLF Tablet Formulation for Clinical Trial}

In preparation for a bLF human clinical trial, we designed custom mixed berry flavored bLF tablet-placebo pairs formulated with either dextrose or sorbitol. To validate that the in vitro efficacy was retained for these formulated tablets, we tested them in the previously described image-based anti-SARS-CoV-2 assay. Placebo and active samples were tested in 10-point, 2-fold dilution from a top concentration of $400 \mu \mathrm{g} / \mathrm{mL}(\mathrm{n}=$ $3)$. The results of this experiment are shown in Figure 6 . We found that the excipients (dextrose and sorbitol) did not influence the potency of the sample. Doseresponse curves for these samples are shown in Figure $6 \mathrm{~A}$. When the $\mathrm{IC}_{50}$ values were corrected to reflect the concentration of bLF in the sample, there was no significant difference between the formulated samples and the bLF standard (Figure 6B). A summary of the results is shown in Figure 6C. Taken together, these data validate that there is no formulation-dependent drop in efficacy and that these placebo-sample pairs would be a viable option for an anti-SARS-CoV-2 clinical trial.

\section{DISCUSSION}

We designed an image-based in vitro assay for SARSCoV-2 infection using the human cell line H1437 to investigate the antiviral properties of bLF and other dairy products. This custom assay used the techniques of high-content fluorescence imaging and analysis, which yields thousands of cell observations per experiment and results in highly robust data. This assay technique is superior to traditional biochemical readouts because data are collected at an individual cell level and information on cell morphology can be collected. For this experiment, we hypothesized that these dairy products might have an independent activity or higher antiviral potency than purified bLF alone due to the presence of additional bioactive proteins or peptides. In total, we assayed 9 different dairy samples including whey protein isolates, concentrates, and enriched LF products. Whey protein isolates and other purified dairy products have demonstrated activity against viruses in the past (Pan et al., 2006); however, we did not observe efficacy for these samples against SARS-CoV-2. We found that when there was efficacy for a sample, it was correlated with the fraction of bLF, suggesting that the antiviral activity was from bLF alone. The highest efficacy was observed for Bioferrin 2000 samples (mean $\pm \mathrm{SEM} ; \mathrm{IC}_{50}=21.8 \pm 1.2 \mu \mathrm{g} / \mathrm{mL}$, WA1 strain) which contain $>90 \%$ bLF. Of note, there were no statistically significant differences between the $\mathrm{IC}_{50}$ of efficacious samples when corrected for their percent bLF, which demonstrates that bLF retains in vitro potency when in combination with other dairy proteins and peptides. The potency of bLF in H1437 $(20.0 \pm 1.2 \mu \mathrm{g} / \mathrm{mL}$, 
WA1 strain) is consistent with our previously reported results in Huh7 $(26.8 \mu \mathrm{g} / \mathrm{mL}$, WA1 strain; Mirabelli et al., 2021), which further supports that efficacy is independent of the cell line.

Given that the efficacy of these dairy products seemed to be solely from bLF, the remainder of our project was focused on expanding upon previous data and providing support for using bLF as an anti-SARS-CoV-2 therapeutic. To establish broad-spectrum activity, we tested bLF and its peptic cleavage product, lactoferricin $\mathrm{B}$, against several SARS-CoV-2 variants including the WA1 (wild type), B.1.1.7 (UK), B.1.351 (South African), P.1 (Brazilian), and Delta (Indian) strains.
We found that bLF has efficacy against all strains that were tested (Figure 4) and expect that it would also have activity against additional emergent strains in the future. Of the variants tested, bLF had the highest potency against the B.1.1.7 strain. Several mutations have been noted in B.1.1.7 with the N501Y mutation being a key mutation on the spike binding protein that increases affinity to the receptor-binding domain (Ramanathan et al., 2021). The variation in bLF efficacy against variants may be due to their differential affinities for cell surface HSPG, which aid in viral entry. A variant with a higher affinity for HSPG may be able to displace bLF molecules at lower concentrations and

\section{A.)}

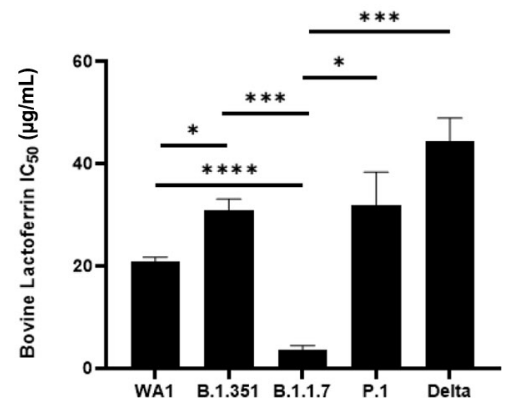

B.)

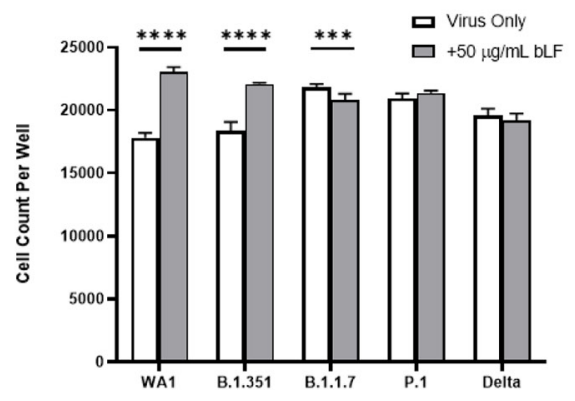

C.)

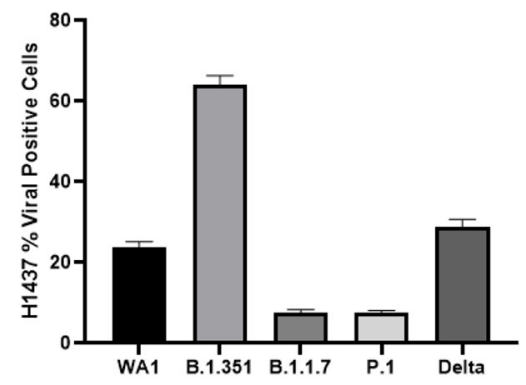

D.)

WA1

B.1.351

B.1.1.7

P.1

Delta
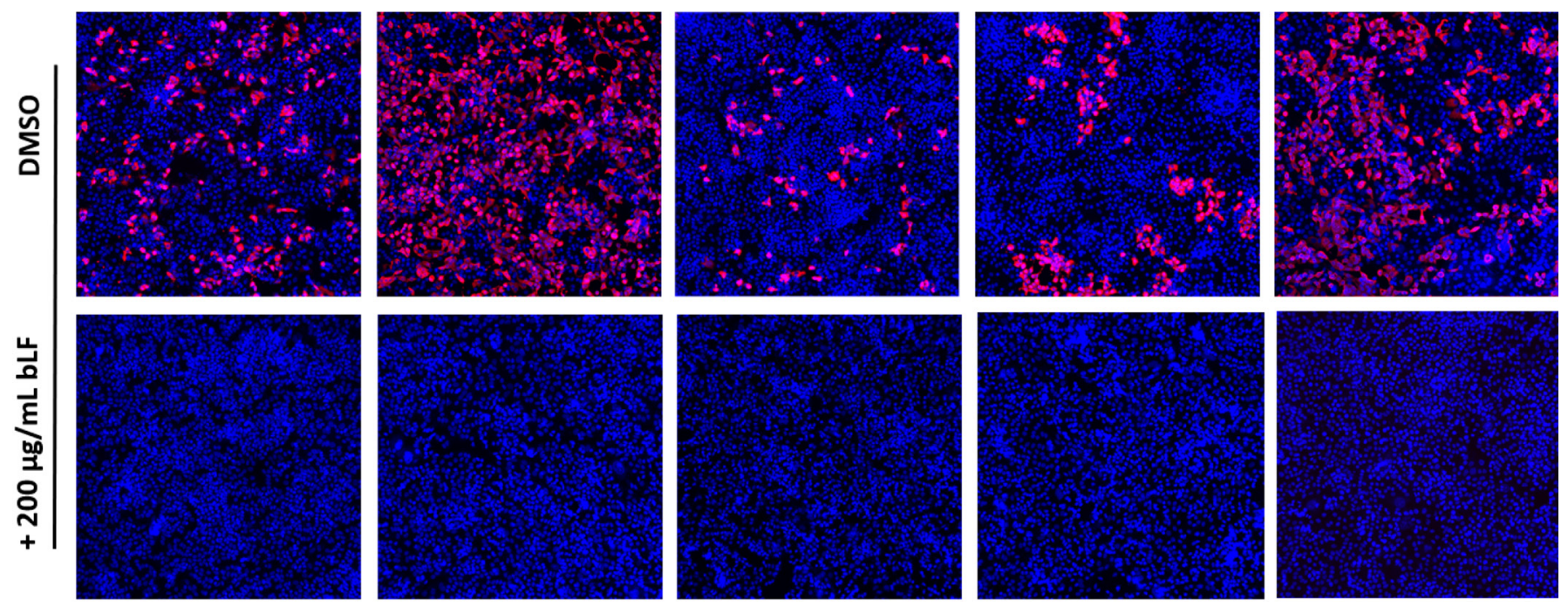

Figure 4. Efficacy of bovine lactoferrin (bLF) against SARS-CoV-2 variants of concern. (A) Half-maximal inhibitory concentration (IC ${ }_{50}$ ) values for bLF in $\mathrm{H} 1437$ cells against various SARS-CoV-2 strains. All viral strains were evaluated at a multiplicity of infection of 5 . The $\mathrm{IC}_{50}$ values were determined using GraphPad Prism 9, and data represent the mean \pm SEM from $\mathrm{n}=4$ replicates. Statistical significance was determined using Student's $t$-tests with Welch's correction in GraphPad Prism $9\left({ }^{*} P<0.05,{ }^{* * *} P<0.001,{ }^{* * * *} P<0.0001\right)$. (B) Cell counts/well for viral controls versus treatment with $50 \mu \mathrm{g} / \mathrm{mL}$ bLF. Data show a significant recovery $(* * * * P<0.0001)$ of cell viability following treatment with bLF for WA1 and B.1.351 viral strains. (C) Percentage of viral nucleocapsid protein (NP)-positive cells at a multiplicity of infection $=5$ for the different variants. The B.1.351 infection resulted in the highest number of infected cells after $72 \mathrm{~h}$. The raw percentages of infection for all variants were significantly different from one another at $P<0.0001$ except for B.1.1.7. and P.1, which did not differ. (D) Representative images for viral controls (dimethyl sulfoxide, DMSO) and infected cells treated with $200 \mu \mathrm{g} / \mathrm{mL}$ bLF. Images (10× magnification) are an overlay of cell nuclei (blue) and SARS-CoV-2 NP protein (red). Images were produced using ImageJ software (National Institutes of Health). 
would thus result in a less potent $\mathrm{IC}_{50}$ value. Future research efforts regarding SARS-CoV-2 variants and bLF should include studying the strengths of each variant's association with cell surface HSPG. The strength of viral association should then be compared with the strength of bLF's association with HSPG. This might help explain why bLF has degrees of efficacy in viral inhibition and increased potency against B.1.1.7 even though literature shows that B.1.1.7 has a higher binding affinity with the ACE2 receptor (Shahhosseini et al., 2021). Additionally, there may be a direct binding interaction between bLF and the spike protein, which is variable among the SARS-CoV-2 variants and could also explain the variable potencies. Previous research has demonstrated that bLF directly binds and inhibits several other viruses including adenovirus, feline herpes virus (FHV-1), hepatitis $\mathrm{C}$ virus (HCV), and human immunodeficiency virus (HIV); however, additional research is needed to confirm direct binding to SARSCoV-2 (Redwan et al., 2014).

In this project, we screened multiple dairy ingredients for anti-SARS-CoV-2 activity (Table 1 ). Whey proteins and hydrolyzed whey protein have been shown to have a wide range of bioactive characteristics including bioactive peptides that are encrypted in the primary structure and released during protein hydrolysis (Minj and Anand, 2020). Our screening indicated that the inhibition of SARS-CoV-2 was strongly correlated with the level of bLF that was found in the sample and was specific for bLF.

One of the encrypted peptides found in bLF is lactoferricin f17-41 of LF and is produced during digestion. It has been shown to have broad antimicrobial and antiviral characteristics as an inhibitor of bacteria, yeasts, fungi, and viruses and can function as an immune-modulatory peptide (Gifford et al., 2005). Our research indicated that lactoferricin inhibited SARS$\mathrm{CoV}-2$, although it required significantly greater concentrations for inhibition (Figure 5). The inhibition, although significant, did not appear linearly dependent on concentration for all strains. The nonlinear nature of the inhibition may be due to a nonspecific mechanism of action involving viral membrane disruption due to the highly cationic nature of the peptide. The high concentration needed to achieve significant efficacy also supports a nonspecific mechanism of action. Further research is needed to confirm a mechanism of action for lactoferricin.

The immune modulation of bLF is of interest because it provides an indirect method to inhibit viral replica-
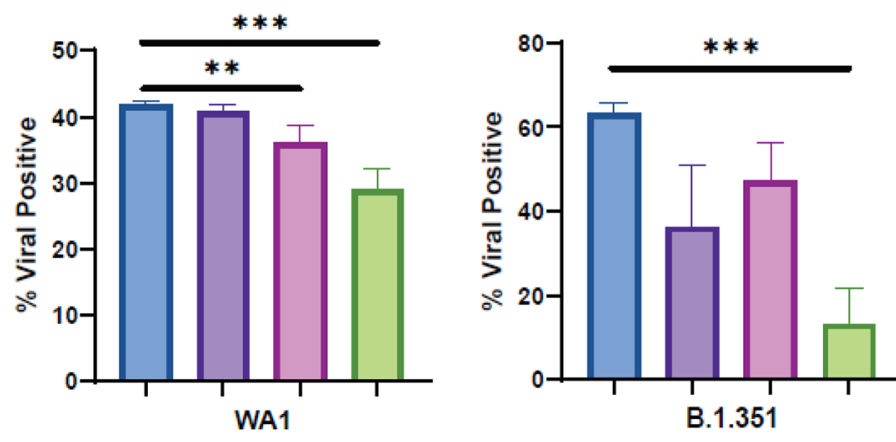

चeh + SCV2
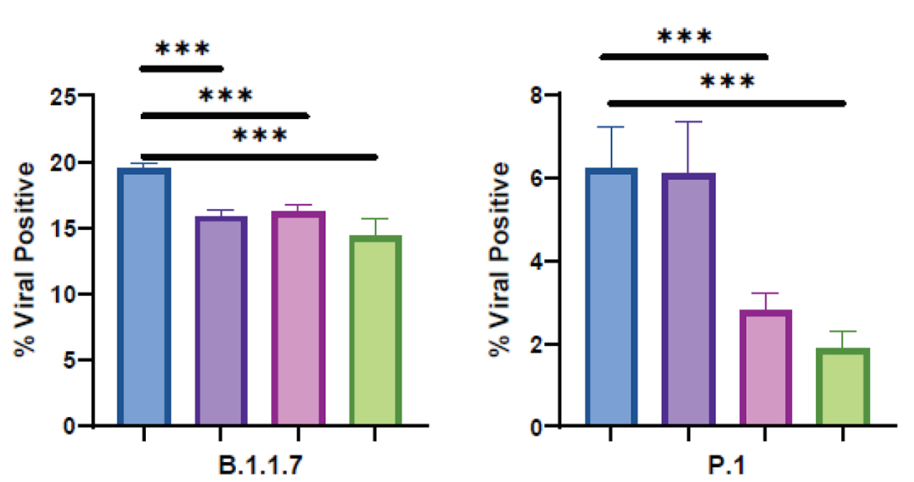

$50 \mu \mathrm{g} / \mathrm{mL}$ bLF $17-41$

$100 \mu \mathrm{g} / \mathrm{mL}$ bLF $17-41$

$200 \mu \mathrm{g} / \mathrm{mL}$ bLF $17-41$

Figure 5. Bovine lactoferricin 17-41 has modest anti-SARS-CoV-2 activity in vitro. Bar chart comparing 3 concentrations (50, 100, and 200 $\mu \mathrm{g} / \mathrm{mL}$ ) of bovine lactoferrin 17-41 against 4 of the most common SARS-CoV-2 (SCV2) variants of concern: WA1, B.1.351 (South African), B.1.1.7 (UK), and P.1 (Brazilian). Data represent the average \pm SEM for $n=4$ replicates per condition. The raw percentages of infection for lactoferricin-treated cells are shown compared with their vehicle (Veh) control (cell culture medium without lactoferricin) for each variant. Bovine lactoferrin 17-41 was effective at diminishing the percentage viral positivity within each of the strains in a dose-dependent manner. Significance was determined using Student's $t$-test with Welch's correction in GraphPad Prism $9\left(* * P<0.01,{ }^{* * *} P<0.001\right)$. 
A.)
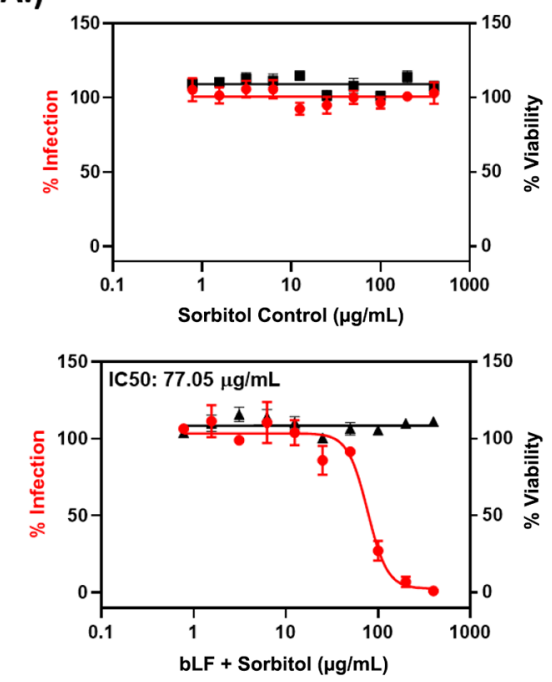

C.)

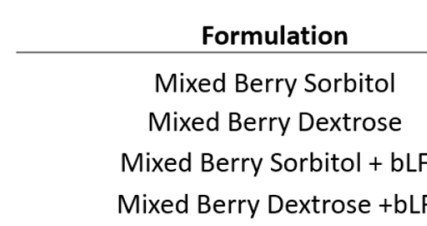

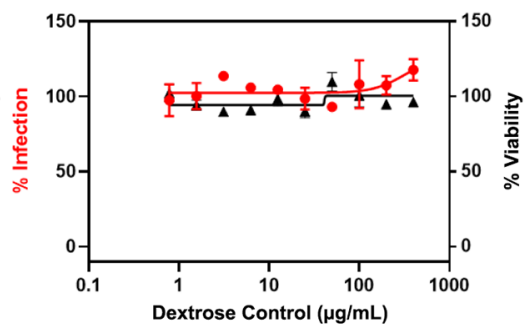

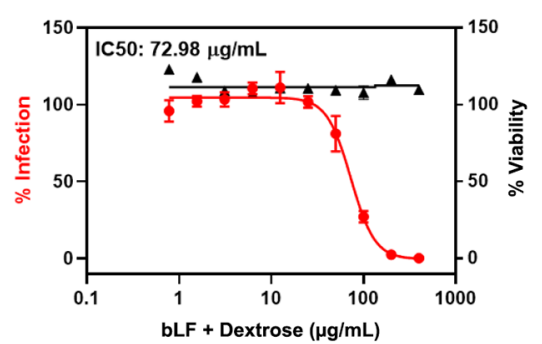

bLF + Dextrose $(\mu \mathrm{g} / \mathrm{mL})$
B.)

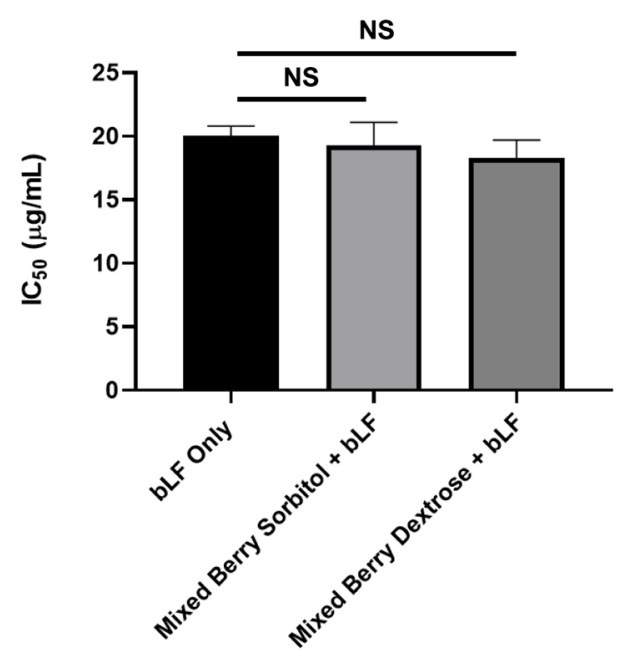

Figure 6. Efficacy of bovine lactoferrin (bLF) tablet formulations for human clinical trials. (A) Dose-response curves for the different lactoferrin formulations examined. The formulated samples containing bLF exhibited a significant reduction of SARS-CoV-2 infection with halfmaximal inhibitory concentration $\left(\mathrm{IC}_{50}\right)$ for bLF formulated in sorbitol or dextrose at 77.05 and $72.98 \mu \mathrm{g} / \mathrm{mL}$, respectively. Sorbitol and dextrose controls did not affect the percentage of SARS-CoV-2 infection as single agents without bLF. Curves were fit in GraphPad Prism 9 using a 4-parameter semi-log variable slope model. (B) $\mathrm{IC}_{50}$ comparison between purified bLF and bLF formulated with either dextrose or sorbitol. The $\mathrm{IC}_{50}$ values reported are corrected to reflect the percentage of bLF in the sample. Data are shown as the average $\pm \mathrm{SEM}$ of $\mathrm{n}=4$ replicates. There was no statistical significance between formulated and unformulated samples. Significance was determined using Student's $t$-tests with Welch's correction in GraphPad Prism 9. (C) Summary table comparing formulated samples and controls. CC $50=50 \%$ cytotoxic concentration. $\mathrm{NA}=$ not applicable.

tion and potentially ameliorate disease progression. A recent review article (Zimecki et al., 2021) summarized in vivo and in vitro research that shows strong support for LF to modulate the immune system and suggested that it may be a good candidate to reduce the severity of SARS-CoV-2 infection. Transcriptomic analysis study showed that uninfected Caco-2 intestinal epithelial cells in the presence of bLF upregulated key expression of antiviral cytokines (IFNA and IFNA1), receptors (TLR3 and TLR7) that are used to sense viruses, and also an upregulation of innate immunity response signaling (IRF3, IRF7, and MAVS; Salaris et al., 2021). This provides 2 interesting areas of future research for bLF to better understand the in vitro inhibition of viral binding and attachment and the indirect effect of immune modulation on viral infection and replication.

One research area that is lacking is human clinical data to support in vitro research. Bovine lactoferrin delivery in tablet or capsule form can be easily produced but it was not known if common excipients would interfere with bLF's ability to inhibit viral inhibition in vitro. Figure 6 shows that neither dextrose or sorbitol inhibits or prevents the antiviral activity of LF. When standardized for bLF content, the results were not significantly different than purified bLF. These types of tablets could be used in a human clinical study.

Finally, a key advantage for bLF as a potential SARS-CoV-2 therapeutic is its robust supply chain and widespread availability. Purified bovine LF has been available for several decades with an estimated production of 350 to $400 \mathrm{Mt}$ in 2020 (Whey Book, 2020). Much of the commercially available LF is added to infant formula or sold as a dietary supplement. Lactoferrin is also designated by the Food and Drug Administration as generally recognized as safe (GRAS). In contrast, one potential limitation to the usage of bLF for SARSCoV-2 infection is that due to the short half-life of bLF, in vitro $\mathrm{IC}_{90}$ concentrations are not likely to be reached in human serum for long periods of time. However, the systemic immunomodulatory activity induced by LF and proteolytic cleavage products such as lactoferricin $\mathrm{B}$ is not modeled in vitro, and additional activity may 
be present at a whole-organism level. It is likely that a different formulation strategy, such as an enteric-coated tablet (avoids peptic digestion) or an inhalable powder (direct targeting to lungs) would be ideal for achieving appropriate concentrations of bLF to inhibit virus. Another option for increasing to potential of bLF as an anti-SARS-CoV-2 therapeutic would be to use it as a combination therapy with other natural products or antivirals. This has been demonstrated in vitro in a synergy study with remdesivir where the 2 individual agents had additive efficacy against SARS-CoV-2 (Mirabelli et al., 2021).

Overall, the availability and strong safety profile of bLF make it a strong candidate for both prophylactic and therapeutic anti-SARS-CoV-2 applications. Future work will be needed to fully understand the antiviral potential for bLF in a clinical setting.

\section{CONCLUSIONS}

Bovine lactoferrin exhibits a wide spectrum of antiviral activity in vitro against variants of SARS-CoV-2 including South African B.1.351, UK B.1.1.7, Brazilian P.1, and Indian Delta variants. Several sources of dairy proteins and bioactive peptides were screened for antiviral activity but antiviral activity was specific for bLF and correlated to the bLF content in dairy ingredients. Lactoferricin B, a degradation product of bLF, also has weak anti-SARS-CoV-2 efficacy, which could add to its clinical significance. Dextrose and sorbitol, common excipients used in manufacturing tablets, did not interfere with the ability of bLF to inhibit SARS-CoV-2. The availability, safety, and in vitro efficacy of bLF make it a promising candidate for future research in combating SARS-CoV-2.

\section{ACKNOWLEDGMENTS}

We acknowledge funding from the University of Michigan Institute for Clinical and Health Research (MICHR; National Center for Advancing Translational Science Grant UL1TR002240) and its Center for Drug Repurposing. JZS is supported by the National Institute of Diabetes and Kidney Diseases (R01DK120623). JWW is supported by the University of Michigan Pharmacological Sciences Training Program (PSTP) T32 training grant. We thank Carla Pretto-Kernahan and Carmen Mirabelli (both of University of Michigan Medical School) for thoughtful discussions and for helping prepare viral stocks for our experiments. Loren Ward is employed by Glanbia Nutritionals and participates in a long-term incentive plan; Glanbia Nutritionals produced the Bioferrin and other dairy ingredients used in the study. The other authors have not stated any conflicts of interest.

\section{REFERENCES}

Aleem, A., A. B. Akbar Samad, and A. K. Slenker. 2021. Emerging Variants of SARS-CoV-2 And Novel Therapeutics Against Coronavirus (COVID-19). in StatPearls. StatPearls Publishing LLC.

Challen, R., E. Brooks-Pollock, J. M. Read, L. Dyson, K. TsanevaAtanasova, and L. Danon. 2021. Risk of mortality in patients infected with SARS-CoV-2 variant of concern 202012/1: Matched cohort study. BMJ 372:n579. https://doi.org/10.1136/bmj.n579.

Chang, R., T. B. Ng, and W. Z. Sun. 2020. Lactoferrin as potential preventative and adjunct treatment for COVID-19. Int. J. Antimicrob. Agents 56:106118. https://doi.org/10.1016/j.ijantimicag .2020.106118.

Cutone, A., L. Rosa, G. Ianiro, M. S. Lepanto, M. C. Bonaccorsi di Patti, P. Valenti, and G. Musci. 2020. Lactoferrin's anti-cancer properties: Safety, selectivity, and wide range of action. Biomolecules 10:456. https://doi.org/10.3390/biom10030456.

Davies, N. G., S. Abbott, R. C. Barnard, C. I. Jarvis, A. J. Kucharski, J. D. Munday, C. A. B. Pearson, T. W. Russell, D. C. Tully, A. D. Washburne, T. Wenseleers, A. Gimma, W. Waites, K. L. M. Wong, K. van Zandvoort, J. D. Silverman, K. Diaz-Ordaz, R. Keogh, R. M. Eggo, S. Funk, M. Jit, K. E. Atkins, and W. J. Edmunds. 2021. Estimated transmissibility and impact of SARS-CoV-2 lineage B.1.1.7 in England. Science 372:eabg3055. https://doi.org/10 .1126 /science.abg3055.

Dong, E., H. Du, and L. Gardner. 2020. An interactive web-based dashboard to track COVID-19 in real time. Lancet Infect. Dis. 20:533-534. https://doi.org/10.1016/S1473-3099(20)30120-1.

Egashira, M., T. Takayanagi, M. Moriuchi, and H. Moriuchi. 2007. Does daily intake of bovine lactoferrin-containing products ameliorate rotaviral gastroenteritis? Acta Paediatrica 96:1242-1244.

Elzoghby, A. O., M. A. Abdelmoneem, I. A. Hassanin, M. M. Abd Elwakil, M. A. Elnaggar, S. Mokhtar, J. Y. Fang, and K. A. Elkhodairy. 2020. Lactoferrin, a multi-functional glycoprotein: Active therapeutic, drug nanocarrier \& targeting ligand. Biomaterials 263:120355. https://doi.org/10.1016/j.biomaterials.2020.120355.

Gifford, J. L., H. N. Hunter, and H. J. Vogel. 2005. Lactoferricin. Cell. Mol. Life Sci. 62:2588-2598. https://doi.org/10.1007/s00018-005 $-5373-\mathrm{z}$.

Hoffmann, M., H. Kleine-Weber, S. Schroeder, N. Krüger, T. Herrler, S. Erichsen, T. S. Schiergens, G. Herrler, N. H. Wu, A. Nitsche, M. A. Müller, C. Drosten, and S. Pöhlmann. 2020. SARS-CoV-2 cell entry depends on ACE2 and TMPRSS2 and is blocked by a clinically proven protease inhibitor. Cell 181:271-280 e278. https:/ /doi.org/10.1016/j.cell.2020.02.052.

Hu, Y., X. Meng, F. Zhang, Y. Xiang, and J. Wang. 2021. The in vitro antiviral activity of lactoferrin against common human coronaviruses and SARS-CoV-2 is mediated by targeting the heparan sulfate co-receptor. Emerg. Microbes Infect. 10:317-330. https:// doi.org/10.1080/22221751.2021.1888660.

Jenssen, H., and R. E. Hancock. 2009. Antimicrobial properties of lactoferrin. Biochimie 91:19-29. https://doi.org/10.1016/j.biochi .2008.05.015.

Lang, J., N. Yang, J. Deng, K. Liu, P. Yang, G. Zhang, and C. Jiang. 2011. Inhibition of SARS pseudovirus cell entry by lactoferrin binding to heparan sulfate proteoglycans. PLoS One 6:e23710. https://doi.org/10.1371/journal.pone.0023710.

Legrand, D., and J. Mazurier. 2010. A critical review of the roles of host lactoferrin in immunity. Biometals 23:365-376. https://doi .org/10.1007/s10534-010-9297-1.

McQuin, C., A. Goodman, V. Chernyshev, L. Kamentsky, B. A. Cimini, K. W. Karhohs, M. Doan, L. Ding, S. M. Rafelski, D. Thirstrup, W. Wiegraebe, S. Singh, T. Becker, J. C. Caicedo, and A. E. Carpenter. 2018. CellProfiler 3.0: Next-generation image processing for biology. PLoS Biol. 16:e2005970. https://doi.org/10.1371/ journal.pbio.2005970. 
Minj, S., and S. Anand. 2020. Whey proteins and its derivatives: Bioactivity, functionality, and current applications. Dairy 1:233-258. https://doi.org/10.3390/dairy1030016.

Mirabelli, C., J. W. Wotring, C. J. Zhang, S. M. McCarty, R. Fursmidt, C. D. Pretto, Y. Qiao, Y. Zhang, T. Frum, N. S. Kadambi, A. T. Amin, T. R. O'Meara, J. R. Spence, J. Huang, K. D. Alysandratos, D. N. Kotton, S. K. Handelman, C. E. Wobus, K. J. Weatherwax, G. A. Mashour, M. J. O'Meara, A. M. Chinnaiyan, and J. Z. Sexton. 2021. Morphological cell profiling of SARS-CoV-2 infection identifies drug repurposing candidates for COVID-19. Proc. Natl. Acad. Sci. USA 118:e2105815118. https:// doi.org/10.1073/pnas.2105815118.

Moreno-Expósito, L., R. Illescas-Montes, L. Melguizo-Rodríguez, C. Ruiz, J. Ramos-Torrecillas, and E. de Luna-Bertos. 2018. Multifunctional capacity and therapeutic potential of lactoferrin. Life Sci. 195:61-64. https://doi.org/10.1016/j.lfs.2018.01.002.

Nappi, C., G. A. Tommaselli, I. Morra, M. Massaro, C. Formisano, and C. Di Carlo. 2009. Efficacy and tolerability of oral bovine lactoferrin compared to ferrous sulfate in pregnant women with iron deficiency anemia: a prospective controlled randomized study. Acta Obstet. Gynecol. Scand. 88:1031-1035. https://doi.org/10 .1080/00016340903117994.

OECD. 2021. Coronavirus (COVID-19) vaccines for developing countries: An equal shot at recovery. https://www.oecd.org/ coronavirus/policy-responses / coronavirus-covid-19-vaccines-for -developing-countries-an-equal-shot-at-recovery-6b0771e6/.

Pan, Y., A. Lee, J. Wan, M. J. Coventry, W. P. Michalski, B. Shiell, and H. Roginski. 2006. Antiviral properties of milk proteins and peptides. Int. Dairy J. 16:1252-1261. https://doi.org/10.1016/j .idairyj.2006.06.010.

Parrow, N. L., R. E. Fleming, and M. F. Minnick. 2013. Sequestration and scavenging of iron in infection. Infect. Immun. 81:3503-3514. https://doi.org/10.1128/IAI.00602-13.

Ramanathan, M., I. D. Ferguson, W. Miao, and P. A. Khavari. 2021. SARS-CoV-2 B.1.1.7 and B.1.351 spike variants bind human ACE2 with increased affinity. Lancet Infect. Dis. 8:1070 https:// doi.org/10.1016/S1473-3099(21)00262-0.

Redwan, E. M., V. N. Uversky, E. M. El-Fakharany, and H. Al-Mehdar. 2014. Potential lactoferrin activity against pathogenic viruses. C. R. Biol. 337:581-595. https://doi.org/10.1016/j.crvi.2014.08.003.

Reed, L. J., and H. Muench. 1938. A simple method of estimating fifty per cent endpoints. Am. J. Epidemiol. 27:493-497. https:// doi.org/10.1093/oxfordjournals.aje.a118408.

Rosa, L., A. Cutone, M. S. Lepanto, R. Paesano, and P. Valenti. 2017. Lactoferrin: A natural glycoprotein involved in iron and inflammatory homeostasis. Int. J. Mol. Sci. 18:1985. https://doi.org/10 $.3390 /$ ijms18091985.

Salaris, C., M. Scarpa, M. Elli, A. Bertolini, S. Guglielmetti, F. Pregliasco, C. Blandizzi, P. Brun, and I. Castagliuolo. 2021. Protective effects of lactoferrin against SARS-CoV-2 infection in vitro. Nutrients 13:328. https://doi.org/10.3390/nu13020328.

Shahhosseini, N., G. G. Babuadze, G. Wong, and G. P. Kobinger. 2021. Mutation signatures and in silico docking of novel SARSCoV-2 variants of concern. Microorganisms 9:926. https://doi.org/ 10.3390/microorganisms9050926.

Siqueiros-Cendón, T., S. Arévalo-Gallegos, B. F. Iglesias-Figueroa, I. A. García-Montoya, J. Salazar-Martínez, and Q. Rascón-Cruz. 2014. Immunomodulatory effects of lactoferrin. Acta Pharmacol. Sin. 35:557-566. https://doi.org/10.1038/aps.2013.200.

Spinelli, A., and G. Pellino. 2020. COVID-19 pandemic: Perspectives on an unfolding crisis. Br. J. Surg. 107:785-787. https://doi.org/ 10.1002/bjs.11627.
Spinner, C. D., R. L. Gottlieb, G. J. Criner, J. R. Arribas López, A. M. Cattelan, A. Soriano Viladomiu, O. Ogbuagu, P. Malhotra, K. M. Mullane, A. Castagna, L. Y. A. Chai, M. Roestenberg, O. T. Y. Tsang, E. Bernasconi, P. Le Turnier, S. C. Chang, D. SenGupta, R. H. Hyland, A. O. Osinusi, H. Cao, C. Blair, H. Wang, A. Gaggar, D. M. Brainard, M. J. McPhail, S. Bhagani, M. Y. Ahn, A. J. Sanyal, G. Huhn, and F. M. Marty. 2020. Effect of remdesivir vs standard care on clinical status at 11 days in patients with moderate COVID-19: A randomized clinical trial. JAMA 324:1048-1057. https://doi.org/10.1001/jama.2020.16349.

Supasa, P., D. Zhou, W. Dejnirattisai, C. Liu, A. J. Mentzer, H. M. Ginn, Y. Zhao, H. M. E. Duyvesteyn, R. Nutalai, A. Tuekprakhon, B. Wang, G. C. Paesen, J. Slon-Campos, C. López-Camacho, B. Hallis, N. Coombes, K. R. Bewley, S. Charlton, T. S. Walter, E. Barnes, S. J. Dunachie, D. Skelly, S. F. Lumley, N. Baker, I. Shaik, H. E. Humphries, K. Godwin, N. Gent, A. Sienkiewicz, C. Dold, R. Levin, T. Dong, A. J. Pollard, J. C. Knight, P. Klenerman, D. Crook, T. Lambe, E. Clutterbuck, S. Bibi, A. Flaxman, M. Bittaye, S. Belij-Rammerstorfer, S. Gilbert, D. R. Hall, M. A. Williams, N. G. Paterson, W. James, M. W. Carroll, E. E. Fry, J. Mongkolsapaya, J. Ren, D. I. Stuart, and G. R. Screaton. 2021. Reduced neutralization of SARS-CoV-2 B.1.1.7 variant by convalescent and vaccine sera. Cell 184:2201-2211. https://doi.org/10 .1016 /j.cell.2021.02.033.

Tworowski, D., A. Gorohovski, S. Mukherjee, G. Carmi, E. Levy, R. Detroja, S. B. Mukherjee, and M. Frenkel-Morgenstern. 2021. COVID19 drug repository: Text-mining the literature in search of putative COVID19 therapeutics. Nucleic Acids Res. 49(D1):D1113D1121. https://doi.org/10.1093/nar/gkaa969.

Tzou, P. L., K. Tao, J. Nouhin, S. Y. Rhee, B. D. Hu, S. Pai, N. Parkin, and R. W. Shafer. 2020. Coronavirus Antiviral Research Database (CoV-RDB): An online database designed to facilitate comparisons between candidate anti-coronavirus compounds. Viruses 12:1006. https://doi.org/10.3390/v12091006.

Valenti, P., and G. Antonini. 2005. Lactoferrin: An important host defence against microbial and viral attack. Cell. Mol. Life Sci. 62:2576-2587. https://doi.org/10.1007/s00018-005-5372-0.

van der Strate, B. W., L. Beljaars, G. Molema, M. C. Harmsen, and D. K. Meijer. 2001. Antiviral activities of lactoferrin. Antiviral Res. 52:225-239. https://doi.org/10.1016/S0166-3542(01)00195-4.

Virtanen, J., R. Uusitalo, E. Korhonen, K. Aaltonen, T. Smura, S. Kuivanen, S. Pakkanen, S. Mero, A. Patjas, M. Riekkinen, A. Kantele, V. Nurmi, K. Hedman, J. Hepojoki, T. Sironen, E. Huhtamo, and O. Vapalahti. 2021. Reduced neutralization of B.1.351 variant SARS-CoV-2 by convalescent sera of COVID-19 patients. Research Square. https://doi.org/10.21203/rs.3.rs-279522/v1

Wakabayashi, H., H. Oda, K. Yamauchi, and F. Abe. 2014. Lactoferrin for prevention of common viral infections. J. Infect. Chemother. 20:666-671.

Wang, Y., P. Wang, H. Wang, Y. Luo, L. Wan, M. Jiang, and Y. Chu. 2020. Lactoferrin for the treatment of COVID-19. Exp. Ther. Med. 20:272-272. https://doi.org/10.3892/etm.2020.9402.

Whey Book. 2020. Whey Book. Global Market for Whey and Lactose Ingredients 2020-2024. 3A-Consulting.

Zimecki, M., J. K. Actor, and M. L. Kruzel. 2021. The potential for Lactoferrin to reduce SARS-CoV-2 induced cytokine storm. Int Immunopharmacol. 95:107571. https://doi.org/10.1016/j.intimp .2021 .107571 